ISSN: 2594-4827

\title{
REPRESENTAÇÕES SOCIAIS DE DOCENTES SOBRE SEU \\ TRABALHO NO PROGRAMA NACIONAL DE ACESSO AO ENSINO TÉCNICO E EMPREGO (PRONATEC)
}

\author{
Aline Cappelletti Tavares ${ }^{1}$ \\ Rita de Cássia Pereira Lima²
}

\section{RESUMO}

Recebido em: abril/2020

Publicado em: agosto/2020

O estudo objetivou investigar representações sociais de docentes sobre o trabalho que exerciam no Programa Nacional de Acesso ao Ensino Técnico e Emprego (Pronatec), em 2016. Baseou-se na Teoria das Representações Sociais (TRS), aproximando-a da abordagem (auto)biográfica. Foi realizado em uma universidade do Rio de Janeiro, com oito docentes dos cursos de Massoterapia, Segurança do Trabalho, Estética e Farmácia. Entrevistas semiestruturadas foram analisadas com apoio da análise de conteúdo, que orientou a construção de narrativas individuais e reflexões sobre metáforas para compreender significados compartilhados pelo grupo. A metáfora "broto/planta" coordenou o discurso do grupo, significada na ideia de "ter jogo de cintura" e "sair da caixinha" para fazer esse trabalho. A planta em crescimento mostra a necessidade de tempo para dar frutos, reforçando descontinuidades no Brasil em relação a políticas educacionais.

Palavras-chave: representações sociais; docentes; Pronatec; Educação Profissional e Tecnológica.

\section{SOCIAL REPRESENTATIONS OF TEACHERS ABOUT THEIR WORK IN} THE PROGRAMA NACIONAL DE ACESSO AO ENSINO TÉCNICO E EMPREGO (PRONATEC): A REGISTRATION DONE IN 2016

\begin{abstract}
The study aimed to investigate social representations of teachers about their work in the Programa Nacional de Acesso ao Ensino Técnico e Emprego (Pronatec), in 2016. It propose theoretical approaches between the Theory of Social Representations (TSR) and the field of (auto)biographical approach. The research was developed in a university of Rio de Janeiro,

\footnotetext{
1 Programa de Pós-Graduação em Educação (Unesa-RJ). http://orcid.org/0000-0002-5120-9686. E-mail:
} alinecappe@hotmail.com

2 Programa de Pós-Graduação em Educação (Unesa-RJ). https://orcid.org/0000-0002-3055-4915 E-mail: ritaplima2008@gmail.com
\end{abstract}


with eight teachers from the courses of Massage Therapy, Workplace Safety, Aesthetics and Pharmacy. Semi-structured interviews were analyzed with the support of content analysis, which guided the development of individual narratives and reflections on metaphors to understand meanings shared by the group. The metaphor of a growing plant coordinated the group's discourse, signified by the idea of "having a waist game" and "getting out of the box" to do this work. The growing plant shows the need for time to bear fruit, reinforcing discontinuities of educational policies in Brazil.

Keywords: Social representations; teachers; Pronatec; Professional and Technological Education.

\section{INTRODUÇÃO}

Esse estudo expõe elementos que ficaram registrados em uma pesquisa realizada durante a vigência do Programa Nacional de Acesso ao Ensino Técnico e Emprego (Pronatec), proposto pelo governo de Dilma Rousseff em 2011. Dentro de um recorte temporal, sem intenção de exaustividade, a pesquisa tem como pano de fundo a Educação Profissional e Tecnológica (EPT) no Brasil, particularmente a de nível médio, regulada pelo Decreto 5.154/2004 (BRASIL, 2004). Esse decreto manteve a oferta de cursos técnicos, com possibilidade de integrar o Ensino Médio à Educação Profissional Técnica de nível médio. No entanto, ele permite a existência de sistemas e redes distintas, ou seja, a existência de um Ensino Médio Propedêutico e a Profissionalização enquanto etapa autônoma.

$\mathrm{Na}$ tentativa de apresentar uma nova proposta, mesmo que não fosse inovadora em sua essência, para atender às necessidades de mão de obra especializada requisitada pelo crescimento econômico do Brasil e, ao mesmo tempo, à população desfavorecida socioeconomicamente, o Governo Federal lançou uma campanha de incentivo ao Ensino Técnico em todo país, por meio Pronatec, em 2011.

Esse Programa surgiu no bojo de uma série de mudanças políticas com o objetivo de ser uma proposta diferente de valorização do desenvolvimento industrial, a fim de amenizar o hiato existente entre o mercado de trabalho e o processo de qualificação de profissionais. $\mathrm{O}$ Pronatec apresentava cursos variados, em convênio com instituições privadas e públicas. Destinava-se à ampliação da oferta e ao fortalecimento da Educação Profissional e Tecnológica integrada ao Ensino Médio nas redes estaduais, em parceria com o Governo Federal. De acordo com o Programa, a proposta era oferecer cursos de formação inicial e continuada, técnicos, superiores de tecnologia, licenciaturas e programas de pós-graduação. 
Eram cursos rápidos de dois turnos, manhã ou tarde, e abrangiam, geralmente, o período de um ano e meio, dividido em três módulos (BRASIL, 2012).

Antes da criação do Pronatec, Frigotto e Ciavatta (2005) já chamavam a atenção para a solução encontrada por novos decretos e iniciativas políticas quanto à formação de um trabalhador produtivo, porém adestrado e limitado. Nessa perspectiva, a Educação Profissional, dissociada da Educação Básica, geraria uma formação em módulos estanques, de forma superficial e assistencial, o que não garantiria nem a profissionalização necessária e condizente às exigências de um mercado de trabalho cada vez mais desafiador, nem a Educação Básica de fato, aquela que possa oportunizar uma chance de ingresso nos cursos de graduação.

No contexto político que acompanhou o Pronatec, a presente pesquisa tem como objetivo investigar representações sociais de docentes sobre o trabalho que exerciam nesse Programa. Que significados atribuíam a esse trabalho? Como esses significados foram construídos? Com intenção de investigar a produção desses significados pelos professores, adotou-se como fundamentação teórico-metodológica a Teoria das Representações Sociais (TRS), proposta por Serge Moscovici em 1961. Esse referencial tem como base processos de natureza psicossocial que envolvem valores, crenças, normas e saberes construídos no cotidiano. Moscovici (1976/2012) afirma que cada grupo social tem seu sistema de representações que incluem experiências e influências recebidas ao longo da vida, nas interações grupais.

Segundo Jodelet (2001), as representações sociais, enquanto conhecimentos do senso comum, elaborados no dia a dia por grupos sociais, se constituem através das experiências, e de saberes e valores que são transmitidos pela tradição e pela educação, num processo de comunicação social. Por meio da linguagem, os grupos produzem significados a respeito dos objetos que os cercam, os provocam e os ameaçam. A mesma autora se refere ao modo como conhecimentos do senso comum interferem na elaboração psicológica que constitui a representação e como esta elaboração psicológica interfere na interação social.

Como afirma Alves-Mazzotti (2008), o estudo das representações sociais proporciona uma investigação interessante sobre como se formam e funcionam os sistemas de referência na classificação das pessoas e dos grupos, na interpretação dos fatos cotidianos, nas relações com a linguagem e na orientação de condutas e de práticas sociais. 
ISSN: 2594-4827

Jodelet (2001) destaca que o partilhar de ideias contribui para o pertencimento e a adesão coletiva. A linguagem, como portadora de representações, faz parte dos processos de interação social, influenciando, promovendo o consenso e o dissenso, polemizando.

Para melhor compreender os significados construídos por docentes do Pronatec a respeito do trabalho que ali exercem, aproximamos a Teoria das Representações Sociais (TRS) e o campo das narrativas (auto)biográficas. De acordo com Alves-Mazzotti (2015), relacionar a TRS à análise das narrativas (auto)biográficas possibilita entrar em contato com os sentidos, sentimentos e comportamentos do sujeito, identificados no grupo de pertença.

Optamos por essa abordagem multidisciplinar dos aspectos sociais e psicológicos, que envolvem tanto a dimensão cognitiva quanto a dimensão afetiva e social dos sujeitos, presentes na abordagem (auto)biográfica e na TRS. Por um lado, pretendemos investigar a representação social construída e internalizada no grupo de docentes sobre o trabalho no Pronatec. Por outro lado, como afirma Alves-Mazzotti (2015), as histórias de vida podem auxiliar na análise do modo como as representações se formam e contribuir para o estudo de sua permanência ou mudança, por meio do conhecimento da experiência direta do sujeito.

A perspectiva psicossocial, presente tanto na abordagem (auto)biográfica como na TRS, reforça a possibilidade de se investigar a representação social do trabalho no Pronatec pelos docentes, tendo como base suas narrativas de vida e de trabalho. É importante ressaltar as palavras e os discursos como força pela qual as representações estabelecem as versões da realidade compartilhadas pelo grupo. Nesse caminho, acreditamos que investigar a representação social de docentes sobre o seu trabalho desenvolvido no Pronatec, com ênfase em narrativas de vida, poderá contribuir para o campo educacional.

\section{Políticas públicas para Educação Profissional e Tecnológica (EPT) e o Pronatec}

De acordo com Saviani (2007), os contornos do Ensino Profissionalizante no Brasil são traduzidos historicamente pela divisão entre atividades de força física para os homens escravos e atividades intelectuais para os homens livres. Essa divisão gerou uma herança cultural que traz consequências que se arrastam, assumindo outros desdobramentos a cada mudança política e estrutural. Essas ações acabam reproduzindo um modelo que continua excluindo e discriminando, sem que se garanta o direito à educação e ao trabalho com equidade. 
Mantendo um recorte temporal sem exaustividade, como mencionado anteriormente, para acompanhar o desenvolvimento econômico mundial e favorecer o crescimento do país, o governo criou, em 1942, um sistema de ensino paralelo ao oficial - Serviço Nacional de Aprendizagem Industrial - SENAI - com o intuito de preparar aprendizes e oferecer uma formação continuada aos trabalhadores.

Onze anos depois, em 1953, o governo brasileiro se propôs a investir no Ensino Profissionalizante. A Lei 1.826 (BRASIL, 1953) facultava o ingresso em qualquer curso superior a todos que tivessem concluído o curso técnico, obedecendo regras de adaptação do currículo. Mais tarde, a Lei de Diretrizes e Bases (LDB) n. 4.024/1961 (BRASIL, 1961) introduziu uma articulação sem restrições entre o Ensino Secundário e o Profissional, abolindo, do ponto de vista jurídico, a discriminação ao Ensino Profissionalizante por meio da equivalência plena. Contudo, apesar de a legislação estabelecer equivalência, a dualidade não perdeu força, uma vez que os conteúdos exigidos nos processos seletivos ao Ensino Superior continuavam privilegiando os estudantes que tivessem um Ensino Médio ou Técnico de melhor qualidade acadêmica.

Em 1971, o governo militar introduziu modificações na estrutura do ensino no país, entre elas a pretensa eliminação desse dualismo entre escola secundária e técnica. A Lei 5.692 (BRASIL, 1971) estabelecia uma escola de primeiro grau destinada à preparação para o trabalho e de segundo grau à qualificação para o trabalho. A iniciativa não resolveu o problema. As escolas públicas não garantiram o ensino esperado na lei, pois não tinham os recursos materiais e humanos para a qualificação. A evasão e a repetência, também presentes, excluíram a população de baixa renda, retrato de uma vontade política e compromisso pedagógico ainda dualista e desigual.

Em 1996, a LDB 9.394 (BRASIL, 1996) configurava o Ensino Médio como etapa final da Educação Básica e o aluno podia optar entre o Ensino Médio, como aprofundamento do Ensino Fundamental, e o Ensino Médio Técnico Profissionalizante. O Decreto-Lei 2.208/1997 (BRASIL, 1997) destinou ao Ensino Técnico o caráter de complementação do Ensino Médio: o aluno podia iniciar a formação técnica ou fazer as duas formações de forma concomitante. Mais uma vez, um sistema paralelo conservava a estrutura dualista e segmentada da Educação Profissional. 
ISSN: 2594-4827

Posteriormente, a Educação Profissional de nível médio foi regulada pelo Decreto 5.154/2004 (BRASIL, 2004), que manteve a oferta de cursos técnicos e trouxe de volta a possibilidade de integrar o Ensino Médio à Educação Profissional Técnica de nível médio. No entanto, permite a existência de sistemas e redes distintas, ou seja, a existência de um Ensino Médio Propedêutico e a Profissionalização enquanto etapa autônoma.

Percebemos, ao observarmos esse recorte do contexto das políticas para a Educação Profissional e Tecnológica no Brasil, que o direcionamento construtivo que vise às necessidades da demanda e do mercado de trabalho ainda não se concretizou, pois a descontinuidade de iniciativas e de projetos não configura avanços consistentes.

O Pronatec foi situado no âmbito de mudanças políticas com o objetivo de ser uma proposta diferente de valorização do desenvolvimento industrial, amenizando o distanciamento entre o mercado de trabalho e o processo de qualificação profissional. Lima (2012) afirma que o Pronatec foi produto do Projeto de Lei n. 1.209/2011, aprovado praticamente na íntegra e sancionado no dia 26 de outubro de 2011 pela presidente Dilma Rousseff como Lei Federal n. 12.513/11. Consistiu em propiciar "por meio de [...] projetos e ações de assistência técnica e financeira [...] a expansão da rede física", alinhando "a educação profissional técnica de nível médio aos cursos e programas de formação inicial e continuada ou qualificação profissional".

De acordo com MEC, em 2016, dois milhões de vagas estavam previstas para o Pronatec. Seriam mais de 350 mil vagas em cursos técnicos e 1,6 milhão de vagas em cursos de qualificação profissional, com o esforço de diversos parceiros: quinze Ministérios parceiros demandantes; todas as secretarias estaduais de educação, que atuam como demandantes e ofertantes; Institutos Federais de Educação, Ciência e Tecnologia; Sistema S SENAI, SENAC, SENAR e SENAT; e redes estaduais, distrital, municipais e fundações públicas especializadas em Políticas Públicas para Educação Profissional e Tecnológica (EPT) (BRASIL, 2016).

O Pronatec deveria integrar a Educação Básica ao Ensino Superior com a oferta de cursos profissionalizantes em sintonia com as demandas do setor produtivo, com o objetivo de: expandir, interiorizar e democratizar a oferta de cursos técnicos de nível médio presencial e a distância, e de cursos e programas de qualificação profissional; fomentar e apoiar a expansão da rede física de atendimento da EPT; contribuir para a melhoria da qualidade do 
ISSN: 2594-4827

ensino médio público, por meio da articulação com o ensino técnico; ampliar as oportunidades educacionais dos trabalhadores, por meio do incremento da formação, qualificação profissional; estimular a articulação entre a política de EPT e as políticas de geração de trabalho, emprego e renda (Lei $n^{\circ}$ 12.513, de 26 de outubro de 2011) (BRASIL, 2011).

Os objetivos citados são importantes para o enfrentamento do problema do ensino profissional e tecnológico (EPT). Entretanto, é preciso clarear a forma como o governo federal pretendia fazê-lo acontecer. Sabe-se que são iniciativas essenciais para a democratização do acesso à educação no país, mas é necessário fazer uma distinção entre o investimento pretendido pela esfera pública e aquele que é realmente realizado pelo setor. Lima (2012) afirma que todas as mudanças propostas se fundamentam em questões econômicas, entretanto, quase sempre, muito mais justificativas do que justificáveis. Nesse sentido, as reformas educacionais valem mais pelos seus efeitos e interesses do que pelos objetivos anunciados.

Para Ciavatta e Ramos (2011), a matrícula gratuita de Educação Profissional em instituições privadas atrai a sociedade, compensando a baixa qualidade do Ensino Médio público. Além disso, as autoras entendem que as dificuldades de implantação do Ensino Médio integrado se manifestam, inicialmente, como sendo de ordem operacional e conceitual. Porém, essas dificuldades são, na verdade, expressão dos limites estruturais dados pela dualidade de classes, que ganham densidade nas necessidades materiais imediatas e, salvo as escolas da rede federal (Cefet, institutos federais, colégios universitários), pela descrença na eficiência dos setores públicos.

Neves e Pronko (2008, p. 24) esclarecem que a escola "[...] vai se metamorfoseando de acordo com o desenvolvimento das forças produtivas e com as mudanças nas relações de produção, nas relações de poder e nas relações sociais gerais", visando à reprodução material da existência e a coesão social. A expansão do capitalismo monopolista tem alterado a escolaridade mínima para o trabalho simples visando ao aumento de produtividade, através de uma escolaridade básica em virtude do seu grau de generalização.

Com base nessas reflexões, e também nos resultados da pesquisa expostos mais adiante, podemos dizer que os cursos do Pronatec não conseguiam dar continuidade à formação profissional e intelectual dos indivíduos e garantir o crescimento integral dos 
ISSN: 2594-4827

cidadãos, pois ao terminarem o Ensino Médio público, os jovens não tinham garantia de ter adquirido a qualidade mínima satisfatória para prosseguir os seus estudos.

\section{A Teoria das Representações Sociais e as Narrativas (Auto)biográficas}

A Teoria das Representações Sociais (TRS) foi introduzida por Serge Moscovici, em 1961, na França, com o estudo de sua tese de doutorado, La Psychanalyse: Son image et son public, sobre a representação social da psicanálise. O autor investigou o modo como a teoria psicanalítica penetrou no pensamento popular francês e como esse saber científico se transformava, à medida que os sujeitos iam se apropriando dele.

A TRS se apresentou como uma alternativa crítica ao caráter individualista da Psicologia Social, que não considerava o contexto social como fator de investigação do sujeito. Contrário a essa perspectiva de individualização, Moscovici criticava a ideia de "defender uma separação radical entre representações individuais e coletivas e a sugerir que as primeiras deveriam ser do campo da psicologia, enquanto as últimas formariam o objeto da sociologia" (MOSCOVICI, 2007, p. 13).

Moscovici (1976/2012) propôs outra perspectiva, na qual procurava identificar diferentes visões de grupos sociais e como esses grupos interagiam no social. $\mathrm{O}$ autor afirma que cada grupo social tem seu sistema de representações, envolvendo experiências e aspectos da vida e é na representação social de um objeto que é possível perceber como o processo cognitivo interfere no social e como a dinâmica social influencia na elaboração cognitiva do indivíduo, através de códigos sociais, formas de expressão cultural e de experiências do cotidiano.

O estudo de Moscovici (1976/2012) investiga como as pessoas tendem a elaborar teorias oriundas do senso comum por meio de informações que dispõem, a fim de tornar o novo, o desconhecido, uma definição familiar e de fácil entendimento, principalmente quando se trata de assuntos relacionados ao mundo científico, os quais são ressignificados, "esclarecidos" e acomodados internamente a partir de tal apropriação e com a intenção de melhor entendê-los. Jodelet (2002, p. 36) assim define a representação social:

[...] é uma forma de conhecimento, socialmente elaborada e compartilhada, com um objetivo prático, e que contribui para a construção de uma realidade comum a um conjunto social. Igualmente designado como saber de senso comum ou ainda saber ingênuo, natural, essa forma de conhecimento é diferenciada entre outras do conhecimento científico. Entretanto, é tida como 
ISSN: 2594-4827

um objeto de estudo tão legítimo quanto este, devido à sua importância na vida social e à elucidação possibilitadora dos processos cognitivos e das interações sociais.

As pessoas analisam, conversam e pensam sobre os mais diferentes assuntos e elaboram significados. Sá (1998) destaca que uma representação social sempre envolve os sujeitos e algum tema ou objeto, não havendo assim uma representação social sem especificar quem o interpreta e analisa, bem como o alvo desse interesse.

Quanto à formação das representações sociais, dois processos evidenciam a interdependência entre a dimensão psicológica e as condições sociais: a objetivação e a ancoragem. A integração da novidade oriunda do meio social, associando o conceito sobre ela a uma imagem, seria a objetivação. E o vínculo que se dá entre o objeto e as práticas sociais, enraizando-o na cultura do grupo, por meio de valores e crenças expressos em processos de comunicação, seria a ancoragem.

Sobre objetivação, Moscovici (2012, p.100) afirma que esta "faz com que se torne real um esquema conceitual, com que se dê à imagem uma contrapartida material". É por meio da objetivação que é possível "descobrir a qualidade icônica de uma ideia, ou ser impreciso, é reproduzir um conceito em uma imagem". Desse modo, o processo de objetivação extrai imagens para uni-las e reproduzi-las no mundo exterior, dando novas percepções ao que já é conhecido, evidenciando como os elementos representados pela ciência e pelo senso comum se integram a uma determinada realidade social, acomodando-se conforme a capacidade interpretativa dos sujeitos.

Para Moscovici (2012), o processo de ancoragem tem relação dialética com a objetivação na construção das representações. É o modo como o sujeito classifica e nomeia o que lhe está sendo apresentado, relacionando-o a outros conceitos já elaborados e familiarizados anteriormente. A ancoragem permite associações que se relacionam com valores e práticas sociais.

Como as características do sujeito e do objeto são tão importantes na busca pela representação social, escutar as experiências desses sujeitos, seus pensamentos e sentimentos torna-se enriquecedor para se compreender os significados do objeto construído por determinado grupo. No intuito de melhor traduzir a relevância e os significados dessas representações construídas e enraizadas no coletivo, a aproximação da TRS com as narrativas (auto)biográficas possibilita melhor compreender o social através das experiências 
ISSN: 2594-4827

individuais, das histórias de vida.

Para Alves-Mazzotti (2015), as narrativas podem auxiliar a evidenciar: a) as relações entre a história individual e a história social; b) a singularidade dos sujeitos que está inserida na história coletiva de suas comunidades; c) os sujeitos como porta-vozes dos grupos sociais com os quais operam; d) a importância das mediações sociais como os grupos de pares. Segundo a autora, as narrativas (auto)biográficas contribuem para estudos em representações sociais porque consideram em que medida os significados, os sentimentos e as condutas são veiculados pelo sujeito e podem explicar e reconhecer os padrões identificados no seu grupo de pertença. Também ajudam a entender o afastamento do sujeito do grupo, levantando hipóteses sobre aspectos subjetivos, vinculados à história individual, às experiências do sujeito, ou às condições concretas nas quais suas práticas se desenvolvem.

Josso (2008) considera que as narrativas de vida são caminhos que permitem tomar consciência das mudanças sociais e culturais do contexto social e profissional, o que valoriza e evidencia a intimidade do sujeito com uma visão simultaneamente singular e socioculturalmente coletiva, repleta de significados.

Sabemos que o sujeito, individual e social ao mesmo tempo, pode dar sentido à vida $\mathrm{e}$ à sua historicidade através da linguagem. Para Bragança (2012), a narrativa dá relevo às experiências, é sempre plural no sentido de captar, através da linguagem, o individual que faz parte do processo coletivo, que dá sentido à sua história, o que permite retratar o perfil do grupo através do indivíduo. Para a autora, a memória é o registro vivo das experiências sociais significativas, que se acumulam ao longo da trajetória pessoal e profissional de cada um, e o trabalho com histórias de vidas se apresenta como possibilidade de análise desses processos de formação e construção de saberes e como resgate dessas experiências.

Portanto, escutar os professores, por meio de narrativas (auto)biográficas, a respeito de suas trajetórias de trabalho, poderá oferecer elementos relevantes para pesquisas no campo da TRS, explicitando, nas representações sociais, a mediação entre o individual e o social, além de, sobretudo, enriquecer as discussões sobre os desafios da Educação. Para Bragança (2012, p. 51), "a narrativa é sempre plural e deve buscar a intensidade das mediações sociais e contextuais que dão sentido à trajetória estudada".

Nas perspectiva das narrativas de vida apresentadas neste estudo, consideramos que o processo biográfico contribui na elaboração da identidade, das ideologias nas quais elas estão 
mergulhadas e na ordem social na qual se inserem. Elas podem ser emancipadoras principalmente no que concerne a atribuírem sentidos, tanto para o indivíduo quanto para a sociedade, relacionados às proprias experiências dos sujeitos.

\section{PERCURSO METODOLÓGICO}

A pesquisa qualitativa foi adotada, devido à intenção de privilegiar significados produzidos pelos sujeitos em suas interações sociais. A pesquisa qualitativa favorece a interação entre o pesquisador e o entrevistado, o que permite a maior compreensão dos contextos e seus significados, motivações, valores e identidades traduzidos pelas experiências pessoais (ALVES-MAZZOTTI; GEWANDSZNAJDER, 1999).

O estudo foi desenvolvido em uma instituição particular, no Rio de Janeiro, que alocava alguns cursos do Pronatec. A ampliação do Programa se deu em função de acordos com instituições privadas e públicas com o objetivo de atender à demanda em muitos bairros da cidade, distribuindo a oferta dos cursos de forma ampla e diversificada.

Os sujeitos formaram um total de oito participantes, todos docentes e ainda atuantes nos cursos quando foram entrevistados. Na época dos encontros, aconteciam as avaliações finais do último módulo da última turma. Os docentes já estavam avisados de que no mês seguinte seriam demitidos porque não haveria a continuidade dos cursos do Pronatec na instituição.

O critério adotado para a escolha desses sujeitos foi a disponibilidade em participar da pesquisa e a certeza de que todos estavam em sala de aula na mesma época e instituição, mesmo que em cursos diferentes. As últimas entrevistas aconteceram na última semana de trabalho dos docentes, que entregavam notas e diários.

Bourdieu (1999) ilustra que, muitas vezes, os pesquisados aproveitam a situação para se fazer ouvir, levar aos outros a sua experiência, seu ponto de vista sobre eles mesmos e sobre o mundo. Por vezes, esses discursos são e dão certo alívio ao pesquisado, pois ao falar, ele reconhece sua singularidade, reflete sobre sua história de vida e sobre o seu papel na sociedade.

As entrevistas semi-dirigidas foram transcritas e seu conteúdo analisado com apoio em Bardin (1994). Essa análise possibilitou a inferência de categorias e de subcategorias. Um formulário de caracterização de perfil buscou identificar o sujeito, sua formação acadêmica, 
ISSN: 2594-4827

idade, tempo de docência e campo de atuação profissional. $\mathrm{O}$ roteiro de entrevistas semidirigidas nos permitiu extrair as experiências significativas de formação antes do Pronatec, a caracterização dos docentes do ensino profissionalizante e tecnológico e a experiência docente nesses cursos.

O momento que antecedeu as entrevistas foi de apreensão, pois era preciso obter um grupo de professores que ainda estivessem atuando como docentes no Pronatec. Cada vez mais o número de cursos ia diminuindo e as turmas sendo encerradas. No apagar das luzes dos cursos técnicos de Farmácia, Massoterapia, Petróleo e Gás, Segurança do Trabalho e Estética, oito docentes foram contemplados. Uma resumida descrição de cada entrevistado será exposta a seguir, com nomes fictícios e informações colhidas no momento das entrevistas, realizadas entre abril e maio de 2016.

Salomão é Doutor em Ciências da Saúde, 55 anos, trinta anos de magistério. No Pronatec, lecionou por dois anos e meio nos cursos de Farmácia, Enfermagem e Segurança no Trabalho.

Fabiano, 36 anos, fez MBA em Gestão Ambiental e é Doutor em Teologia, atuou no Pronatec por quatro anos no curso técnico de Segurança do Trabalho. Tem oito anos de prática docente.

Leandro é biólogo, especialista em Gestão Ambiental e Mestre em Desenvolvimento e Meio Ambiente, tem 32 anos e doze como professor. Atuou no curso técnico de Química e de Estética por um ano e meio.

Luciana, 52 anos, dois anos como professora, é graduada em Farmácia, especialista em Laboratório de Saúde Pública e lecionou no curso técnico de Estética e de Massoterapia por dois anos.

Patricia, 57 anos, é graduada em Comunicação Social e especialista em Docência Superior, EAD e Estética. Leciona há seis anos e atuou no curso de Estética e Massoterapia por dois anos.

Flavia, 43 anos, é graduada em Farmácia e especialista em Homeopatia e Licenciatura para Ensino Fundamental e Médio. Atuou nos cursos de Petroquímica, Petróleo e Gás e Farmácia por dois anos. Leciona há três.

Tânia é graduada em Farmácia e Mestre em Química Orgânica. Tem 52 anos, nove de magistério. Lecionou nos cursos de Farmácia, Massoterapia e Estética por cinco anos. 
ISSN: 2594-4827

Maria, 31 anos, é graduada em Fisioterapia e Doutora em Biologia Celular e Molecular. Atuou nos cursos de Farmácia, Massoterapia e Estética por dois anos. Seu primeiro emprego foi a docência no Pronatec.

\section{RESULTADOS E DISCUSSÕES}

Para Bourdieu (1999), a transcrição da entrevista, que é parte integrante da metodologia do trabalho de pesquisa, não é somente um ato mecânico de passar para o papel o discurso gravado, pois, de alguma forma, o pesquisador deve perceber e interpretar os silêncios, os gestos, os risos, a entonação de voz do informante durante a entrevista. Entretanto, o pesquisador tem o dever de ser fiel ao que foi falado durante a entrevista.

A análise de conteúdo (BARDIN, 1994) ofereceu a base nos resultados aqui apresentados e discutidos. Ela foi conduzida em três etapas: pré-análise, exploração do material e o tratamento dos resultados. A pré-análise consiste em realizar uma leitura "flutuante" das transcrições das entrevistas, identificando os temas mais significativos. $\mathrm{Na}$ fase exploratória, a análise busca codificar e organizar os temas e as suas categorias, assim como os elementos mais significativos em relação ao objeto e os significados, a fim de gerar interpretações para a análise final, do tratamento dos resultados.

O material analisado teve como ponto de partida três unidades temáticas, ou temaschave, com suas categorias: a) "Experiências de vida significativas e formadoras antes do Pronatec": Experiências familiares e escolares; Ensino Superior; Pós-graduação; Ensino Profissionalizante e Técnológico; Experiências Profissionais; b) "Pronatec - aspectos gerais": Acesso; Valorização; Críticas; Sugestões; c) "Docência no Pronatec": Influência de experiências anteriores no EPT; Características importantes de um docente do EPT; Estratégias de aula utilizadas; Dificuldades encontradas; Experiências significativas.

Neste texto optamos por não detalhar a análise categorial temática, mas expor como ela ofereceu os fundamentos para a construção de narrativas de vida individuais, apresentadas a seguir, posteriormente complementadas com metáforas que expressam significados grupais.

Salomão expressa a tranquilidade em ser experiente. Optou pela carreira de docente e teve apoio de seu pai, que o ensinou a valorizar e escolher o que dava prazer e não dinheiro. Seguiu a carreira docente sem referências de professores, além de seu pai. Estudou com docentes tradicionais. Começou a trabalhar muito novo, fez doutorado e tem muita 
ISSN: 2594-4827

experiência no ofício. Sente orgulho quando percebe algum aluno seguindo o seu próprio caminho. Valoriza a elevação intelectual como pessoa e a escolha pelo conhecimento através da pesquisa em cursos de pós graduação. Sobre o Pronatec, lamenta o fim e compara a iniciativa do governo com o mar, que vai e volta. Ressalta que os cursos técnicos profissionalizantes são uma ótima saída para essa demanda específica, que apresenta autoestima baixa; entretanto, afirma que esse público não difere, de forma marcante, dos alunos do primeiro período da graduação. Sugere que os cursos precisam de um enfoque profissional e prático, que o docente precisa da experiência de mercado para melhor atuar em sala de aula, que o curso deveria ser mais qualificado, não permitindo que todos pudessem entrar, que deveria ter uma avaliação diagnóstica para identificar quem tem o real interesse de estudar e não permitir fazer por fazer, porque é gratuito.

Fabiano valoriza o fato do professor ser amigo do aluno. A lembrança do tempo de escoteiro e de um professor de História o faz ressaltar a importância de se ter experiências positivas no universo escolar e como isso o influenciou na escolha de ser um docente que também é, antes de tudo, um amigo do aluno, alguém que ele possa confiar, contar, além de aprender. Professor também do Senac, ele já conhecia a proposta do Pronatec e não teve dificuldade em aprimorar as suas aulas para melhor atender aos alunos. Considera que o professor desses cursos precisa ser dinâmico e objetivo. Para ele, o Pronatec é uma evolução, pois o Brasil tem uma deficiência técnica muito grande, além da carência educacional e cultural. Contudo, percebe que o projeto precisa ser melhorado, como qualquer outro, experimentado e, em seguida, ajustado. Ele acredita na melhoria contínua. Durante as aulas, percebeu o quanto as turmas eram misturadas e o quanto os alunos estavam sedentos em entrar para o mercado de trabalho. Identifica aspectos que poderiam melhorar a qualidade dos cursos: uma triagem que permita identificar a necessidade e aptidão do aluno e a matrícula em um local próximo à sua residência. Em sua visão otimista, os alunos estão preparados porque foram aprovados e acredita que o Pronatec irá continuar porque seria um retrocesso a não continuidade diante de tanta necessidade. Mas que é urgente criar oportunidades de trabalho, ter um sistema integrado com a introdução de estágios. Percebe o Pronatec como uma semente que precisa de cuidados, de condições para crescer. Fabiano se orgulha de ter sido escolhido como paraninfo de turma.

Leandro se preocupa com o desenvolvimento social do indivíduo. Sempre atento a 
todas as informações recebidas, percebe o quanto a sua experiência de filho, de aluno e de educador foi importante para o crescimento e amadurecimento da pessoa e profissional que ele é hoje. Destaca a importância da participação construtiva dos pais na vida dos filhos e do trauma que maus professores podem causar à autoestima dos alunos.A influência de uma professora de Ciências e a leitura de um livro sobre água o fez enxergar a beleza e a urgência da questão ambiental. Escolheu a Biologia para se distanciar dos humanos e trabalhar com animais, mas seu prazer acabou sendo a sensibilidade de perceber a dificuldade do aluno e ajudá-lo como aluno e como cidadão. Filho de trabalhadores da Comlurb ${ }^{3}$, escolheu a educação ambiental como foco em seu mestrado. Encontrou no Pronatec um ideal no projeto, que lhe fez acreditar que finalmente o governo deixaria de ser paternalista para de fato oferecer condições de crescimento aos menos favorecidos. Entretanto, ficou decepcionado ao perceber que o projeto seria passageiro, que não teria continuidade. Lamenta pelos que não conseguiram chegar ao Pronatec, fica feliz ao ver o crescimento de alguns alunos, presenciar a sua transformação, a diferença entre a chegada e a saída.

Luciana relata que seu ambiente doméstico sempre foi movido a conversa, livros, discussões políticas e muita curiosidade, apesar de seus pais terem apenas o segundo grau, a mãe talvez nem isso. Eles sempre foram muito cultos, desde muito nova sempre participou de conversas, o pai gostava de política, tinha amigos que se reuniam para conversar, se acostumou ao ambiente de troca de ideias, de aceitar divergências, trabalhar com as opiniões contrárias. Admiradora de Química e de Biologia, escolheu a Farmácia. Seus professores antigos, desde a alfabetização, Ensino Médio e até mesmo os professores de seus filhos, viraram seus amigos, sabe o nome de quase todos, tem contato com a primeira professora e um bom relacionamento com os educadores dos seus filhos Nunca quis ser professora, mas foi sendo confrontada pelo destino. Começou com os treinamentos na sua área de trabalho, fazendo capacitações como farmacêutica sanitarista do Estado do Rio de Janeiro, multiplicadora pelo Ministério da Saúde. Ao longo de tantos encontros, os alunos e os colegas sempre falavam que tinha muito jeito, que conseguia transmitir muito claramente o que queria. Encontrou no Pronatec o elo entre a docência e a formação de pessoas, o otimismo de Janeiro.

${ }^{3}$ Companhia Municipal de Limpeza Urbana (Comlurb): empresa de limpeza pública na cidade do Rio 
ISSN: 2594-4827

com a vida, a preservação dela em todos os sentidos. Associa o Pronatec a um grande acerto de contas na história do país, porque tem o objetivo de atender a demanda de um público excluído de conhecimento e de oportunidades. Destaca a dificuldade em administrar o número grande de alunos com uma grande diferença de perfis entre eles, a demora do material didático e a evasão. A falta de bagagem escolar e cultural é outro ponto desafiador. Mas quando vê o crescimento do aluno, reforça os seus ideais em ter fé e fascinação pela vida.

Patrícia tem formação em Comunicação Social na UFRJ, pós-graduação em Marketing e Docência Superior. Com uma empresa de consultoria, sempre achou que o seu destino seria longe da sala de aula. Desde pequena via a mãe, professora dedicada e diretora de escola, querida e admirada, como um exemplo de mulher, mas não como um exemplo de profissão. Sempre disse que não queria ser como ela, carregada de livros e preocupada com os alunos. Ela se orgulha de ter sempre estudado em escola pública, por opção e não por falta de posses, até o terceiro ano do Ensino Médio e de ter feito parte de uma educação diferente dos dias atuais, uma educação pública que dava certo, que preparava os alunos de forma cidadã e para dar continuidade aos estudos nas universidades. Desde muito nova seguiu carreira empresarial, ocupou cargos importantes e de chefia em empresas como: TV Globo, Banco Nacional, Mesbla e Volkswagem. Foi a primeira mulher gerente de marketing de automóveis. No meio do caminho, a docência foi aparecendo, primeiramente sendo convidada pelas próprias empresas a capacitar os funcionários, formar novos consultores e vendedores. Em outro momento, foi convidada a dar aula no Cefet, tornou-se professora orientadora do Cefet Junior e quando percebeu, já fazia parte da área acadêmica. Decidiu fazer uma pós-graduação em Estética e foi chamada para coordenar o curso de Estética do Pronatec. Para ela, o Pronatec foi uma excelente oportunidade de "encurtar o caminho da história", pois o aluno acelera a sua chegada ao mercado de trabalho sem passar pela graduação, que é mais demorada. Mas o Pronatec foi um grande desafio para a instituição e também para os professores. A diversidade de perfis em sala de aula e os conflitos que ocorreram fizeram com que qualquer preparação que ela pudesse ter dado aos professores, como coordenadora, fosse pouca. Diz que o Brasil enaltece os intelectos, mas desvaloriza os "braços". Entretanto, acredita que os cursos precisam de reformulações urgentes, começando por esclarecer aos alunos o que é ser profissional, passando pela necessidade de conteúdos teóricos, uma preocupação especial com a evasão e o nivelamento das turmas, o repensar sobre a 
ISSN: 2594-4827

experiência dos primeiros módulos nessa prática inovadora. Confessa que se decepcionou com o projeto, com a descontinuidade, com o resultado, com o descaso do governo, com a desproporção do quanto os professores se dedicaram e do que resultou.

Flavia, farmacêutica, associa suas escolhas na graduação às influências que teve no período escolar. Tanto a disciplina acadêmica quanto a postura em sala de aula de sua professora de Química despertaram o caminho e um desejo a seguir. Outra referência significativa em suas memórias foi a inovação de seu professor de Física, que passava exercícios com cálculos matemáticos, mas lia poemas de sua própria autoria enquanto os alunos faziam. Na família, com predomínio de carreiras voltadas para a administração e economia, ressalta que foi a primeira a procurar a área da saúde. Percebeu o quanto o mercado é ingrato, pois apesar da responsabilidade da função de um farmacêutico, os salários são muito baixos e a sensação é de desvalorização. Fez curso de guia de turismo e começou a trabalhar com turismo pedagógico. A aula que dava aos alunos, dentro do ônibus, associando conhecimento com experiência e vivência, despertou nela a grandeza da relação professor/aluno. Resolveu fazer um curso de Licenciatura para dar aula em colégios e surgiu a oportunidade do Pronatec. Estar em sala de aula, nos cursos do Pronatec, foi desafiador, mas também uma certeza de que havia encontrado o seu caminho. Flavia descobriu que seus alunos não tiveram a sua sorte, não tiveram bons professores no Ensino Médio, não tinham sido nem apresentados à Química ou à Física. Destaca que muitos não sabiam fazer uma soma, nunca viram uma regra de três. Desanimada com o fim dos cursos, lamenta ter sido dessa maneira, acredita que os cursos deveriam continuar realizando ajustes, como o aumento do tempo de duração, a fim de suprir as carências do Ensino Médio; uma orientação inicial aos alunos, antes do início, sobre os cursos, requisitos básicos de atuação no mercado, com o objetivo de evitar ou diminuir a evasão. Considera o Pronatec uma boa tentativa, mas não acredita que é por ele que as necessidades seriam supridas, pois os alunos chegam aos cursos muito despreparados e às vezes são analfabetos funcionais, sem a menor condição de fazer um curso técnico de fato e ingressar no mercado de trabalho. Indignada, acredita que o investimento deveria começar na Educação Infantil, no Fundamental I e II. Lamenta o fim do projeto, apesar de problemático em sua essência, mas fica grata de ver que alguns alunos entram em contato com ela pelo Facebook para agradecer e avisar quando conseguem um emprego. 
ISSN: 2594-4827

Tania foi estudante de curso técnico e acredita, através de sua própria experiência, que esse é o caminho certo para se ter certeza da profissão a escolher na graduação, para se chegar a essa graduação mais preparado e com uma visão de mercado e área de atuação. Trabalhando em um laboratório antes de ingressar na graduação, o contato com bons professores, especialmente o de Química Orgânica, e com farmacêuticos, fez com que optasse pelo curso de Farmácia. Para ela, um docente no técnico profissionalizante deve ser um exemplo e dar motivação para os alunos, deve criar neles o gosto pelo que estão fazendo.. Defende que o professor deve ter o conhecimento profundo da proposta política e pedagógica do Programa, apesar de reconhecer que não tem esse conhecimento. Com experiência no Ensino Técnico Profissionalizante, achou que o trabalho que desenvolveu no Pronatec foi bom, mas sofreu com a falta de apoio de material, xerox e data show, para oferecer aos alunos as aulas dinâmicas e com atividades sobre anatomia. Ela lamenta a falta de ética por parte de colegas e os aborrecimentos que teve, mas reconhece a experiência como positiva no saldo final.

Maria, estudante de pós-doutorado, tem 31 anos e reconhece sua extrema curiosidade em aprender, de piano a desenho, além de seu estudo acadêmico. Estudou o ciclo básico em uma escola pública de Angra dos Reis e tem boas lembranças dos seus professores, cuja influência é evidente tanto na sua formação pessoal como na prática docente. Considera importante repetir as boas vivências que teve e repensar sobre as não boas a fim de não cometer os mesmos exemplos. Considera que teve um bom ensino, o suficiente para se manter numa escola particular quando ingressou no Ensino Médio. Queria Medicina, mas tornou-se fisioterapeuta e se apaixonou pela profissão, depois cursou mestrado, doutorado e teve muita dedicação à pesquisa. Entretanto, sentiu necessidade de dividir seu conhecimento e surgiu o desejo da sala de aula e, como primeira experiência, o Pronatec. Admira a proposta dos cursos técnicos profissionalizantes porque o aluno consegue mais rapidamente ser capacitado para o mercado de trabalho. Dá o exemplo dos próprios alunos do curso que lecionou, pois muitos já estão trabalhando na área. Para ela, o docente do ensino profissionalizante precisa estar bem capacitado, ter muito conhecimento, querer aprender sempre e ser capaz de transmitir o que sabe ao aluno. Tem visão otimista do projeto, da sala de aula e do convívio e ajuda mútua entre professores. Apesar da inexperiência de sala de aula, não sentiu dificuldades em montar as aulas ou lidar com os alunos e suas dificuldades. $\mathrm{O}$ olhar de Maria para a experiência com o Pronatec foi positivo e a amizade que fez com os alunos simboliza o quanto a convivência 
ISSN: 2594-4827

foi produtiva. Ela comenta com orgulho que mantém contato com alguns pelo Facebook e que é sempre avisada sobre as conquistas deles, o que a torna participativa nessa construção e realização profissional. A experiência com o Pronatec foi um marco positivo no seu início de carreira como docente, que teve como ponto forte a facilidade em interagir com os alunos e suas necessidades, como se a descoberta do ambiente de sala de aula fosse também uma descoberta de suas próprias aptidões e desejos.

Através do olhar do sujeito investigador e também sujeito da própria experiência narrativa, "as narrativas sobre as narrativas", anteriormente registradas, têm a motivação de captar a importância e a riqueza da sutileza dos olhares, da vibração da voz, da entonação da fala ao comentar certos assuntos, do movimento corporal e da essência da intencionalidade discursiva.

Josso (2010) afirma que, ao lembrar ou relembrar alguma prática, uma "experiência formadora", entramos em contato com possíveis transformações que tivemos com aquela ação, positivamente ou negativamente, e que esse processo comunicativo é que permite a reflexão, tornando-as reconhecidas como uma "experiência significativa".

Portanto, o sujeito das narrativas é o autor de sua própria história e ao entrar em contato com a sua trajetória, sua bagagem de vida, consegue avaliar o processo de construção do seu ser e do seu caminhar num movimento constante de reestruturação e de interação com o todo. O sujeito, ao reconhecer o seu passado, tornando-o real no momento da fala e da escuta de si mesmo, é capaz de repensar o futuro, dando novos contornos à sua trajetória (BRAGANÇA, 2012).

As narrativas individuais expostas, fundamentadas na análise de conteúdo temática das entrevistas, nos permitem aproximação da TRS por meio de metáforas expressas pelos docentes, as quais contribuem para a proposta de um modelo figurativo da representação social, conforme Moscovici (1976/2012). Das narrativas individuais podemos assim chegar a representações compartilhadas pelo grupo de oito docentes.

Nas entrevistas, uma das questões foi: Se o Pronatec pudesse ser uma coisa, um animal, um vegetal ou um mineral, por exemplo, o que seria? Por quê?, seguindo proposta de Andrade (2006). A técnica de indução de metáforas oferece ao sujeito um contexto diferente da formalidade das entrevistas, oportunizando a descoberta de questões que normalmente ficam submersas na racionalidade 
ISSN: 2594-4827

A metáfora faz parte da linguagem e ajuda na composição da realidade, colabora para a estruturação do conhecimento e da experiência (LAKOFF; JOHNSON, 2002). Segundo Mazzotti (2002), as metáforas sintetizam e ordenam os significados, atuando como uma espécie de modelo que organiza o discurso, coordenando linhas de argumentação e determinando predicativos e categorias. Com o objetivo de remeter os sujeitos ao universo de situações fictícias, provocando respostas pouco convencionais, os sujeitos puderam formalizar e justificar a relação entre o "objeto" metafórico escolhido e sua relação com o Pronatec. (MAZZOTTI, 2002). O Quadro 1 ilustra as resposta dos sujeitos.

Quadro 1: Respostas à questão de indução de metáforas.

\begin{tabular}{|c|c|c|}
\hline SUJEITOS & $\begin{array}{l}\text { QUESTÃO } \\
\text { Se o Pronatec pudesse } \\
\text { ser uma coisa, um } \\
\text { animal, um vegetal ou } \\
\text { um mineral, por } \\
\text { exemplo, o que seria? }\end{array}$ & $\begin{array}{l}\text { JUSTIFICATIVA } \\
\text { Por quê? }\end{array}$ \\
\hline Salomão & Rios & $\begin{array}{l}\text { Os cursos de graduação, pra mim, são como rios } \\
\text { que vão passando pelos alunos. Uns alunos } \\
\text { conseguem aproveitar melhor pelas condições do } \\
\text { rio e outros alunos não conseguem aproveitar tão } \\
\text { bem, né, mas sendo que, a não ser por fatores } \\
\text { externos, a grande maioria consegue se formar que } \\
\text { é o seu objetivo. }\end{array}$ \\
\hline Fabiano & Planta & $\begin{array}{l}\text { Uma planta porque a planta primeiramente é uma } \\
\text { semente. E não basta só você plantar ela, você tem } \\
\text { que cuidar, tem que criar condições pra que ela } \\
\text { cresça, né [...] Quando ela brotar, você tem que } \\
\text { guardar ela das espécies invasoras, das ameaças, } \\
\text { das pragas, de tudo que é tipo de ameaça que atente } \\
\text { contra a vida daquela planta ali. Então, você vai } \\
\text { cuidando dela, vai cuidando, vai orientando, né... } \\
\text { Até que ela produza o fruto, e ele, é o fato, do } \\
\text { espaço de tempo entre a semente e o fruto, é um } \\
\text { caminho... É um trabalho a médio-longo prazo, } \\
\text { você não planta semente hoje e já espera que } \\
\text { amanhã ela dê o fruto... Não, tem todo um processo, } \\
\text { tem todo um trabalho por trás disso... }\end{array}$ \\
\hline Leandro & Medicamento & $\begin{array}{l}\text { Um medicamento porque contribui pra saúde do } \\
\text { indivíduo. É... eu até me emocionei... É... e eu } \\
\text { não pensava, nunca tinha parado pra pensar } \\
\text { dessa forma, que você vai ao médico quando } \\
\text { você tá precisando de algo muito urgente e que } \\
\text { aquele medicamente é injetado na sua veia ou } \\
\text { você toma aquele medicamento, que tira a sua } \\
\text { dor e você se sente bem. Eu vejo o Pronatec da } \\
\text { mesma forma. Pessoas que talvez estivessem } \\
\text { isoladas, perdidas, sem perspectiva de vida e o } \\
\text { Pronatec surgiu como uma luz pra vida dessas }\end{array}$ \\
\hline
\end{tabular}


ISSN: 2594-4827

\begin{tabular}{|c|c|c|}
\hline & & $\begin{array}{l}\text { pessoas, que talvez até tirou uma dor por esse } \\
\text { individuo não se ver capaz de fazer algo, e } \\
\text { agora, ele formado, ele tem a capacidade de agir, } \\
\text { de atuar diferente. }\end{array}$ \\
\hline Luciana & Planta & $\begin{array}{l}\text { Eu acho que seria uma planta porque a planta } \\
\text { frutifica, né... não morre, né... O animal de um } \\
\text { modo geral morre... O mineral é estático, né... } \\
\text { Eu acho que tá muito mais ligado à planta pela } \\
\text { capacidade de se perpetuar, né... Com algumas } \\
\text { modificações aqui, ou ali, mas muito mais pra } \\
\text { planta... }\end{array}$ \\
\hline Patricia & $\begin{array}{l}\text { Broto de alguma } \\
\text { planta }\end{array}$ & $\begin{array}{l}\text { Seria um broto de alguma planta, que a gente } \\
\text { ainda está plantando e não sabe nem que broto é, } \\
\text { porque a gente não recebeu no pacote do broto } \\
\text { "essa é a planta de...”, não, é um broto, o que } \\
\text { sair a gente vai ver, foi meio assim na minha } \\
\text { cabeça, entendeu? É uma coisa que a gente fez } \\
\text { junto, plantou junto e ainda, assim, não se sabe o } \\
\text { que vai colher porque é assim, olha o que } \\
\text { aconteceu com o governo, né, um projeto que } \\
\text { poderia, numa segunda leva, ter sido } \\
\text { aperfeiçoado da primeira, sequer vai existir, } \\
\text { então é assim, plantamos o broto, ele apontou e o } \\
\text { que que é aquilo, a gente ainda não sabe, não vai } \\
\text { saber nunca mais, e aí tá tomando cem, duzentos } \\
\text { aqui da minha área, mais quantos lá e quantos } \\
\text { saíram, né..., é triste, mas..., essa é a minha } \\
\text { sensação, broto de algo... }\end{array}$ \\
\hline Flavia & Livro & $\begin{array}{l}\text { Nossa, não tenho nem ideia, eu não sou muito } \\
\text { criativa. Pronatec sendo uma... um livro vamos } \\
\text { dizer, eu acho que é melhor, porque é onde se } \\
\text { obtém conhecimento, acho que é por aí... }\end{array}$ \\
\hline Tania & Vegetal/Planta & $\begin{array}{l}\text { Seria um vegetal, pra mim. Porque planta, ela tá } \\
\text { crescendo, vai expandindo, né? Eu acho assim, } \\
\text { eu tive bastante frutos, tanto eu ganhei como eu } \\
\text { acredito que os alunos também, uma troca, } \\
\text { aprendi muito também, até assim como atuar, né, } \\
\text { assim em várias classes diferentes, } \\
\text { funcionamento diferente, a gente aprende } \\
\text { constantemente isso, mas acho que deu frutos } \\
\text { bons também. Assim, eu saio com saldo } \\
\text { positivo. Pra mim, eu acho isso. É... crescimento, } \\
\text { crescimento. }\end{array}$ \\
\hline Maria & Outro/diamante & $\begin{array}{l}\text { Ah, eu acho que seria um ouro, né, porque você } \\
\text { dá chance, né, você entrega ali aquele ouro, não } \\
\text { sei se um ouro, mais um diamante, né, que se o } \\
\text { aluno consegue lapidar, se o aluno consegue } \\
\text { estudar, ele consegue atingir, né, o que ele quer, } \\
\text { que é o mercado de trabalho, consegue se inserir } \\
\text { no mercado de trabalho e até modificar a vida } \\
\text { dele, porque você vê que tem vários alunos que } \\
\text { passam por muita situação, que aquilo é a } \\
\text { esperança dele pra poder conseguir um emprego, } \\
\text { né, então acho que seria um diamante que } \\
\text { depende de ser lapidado tanto do professor }\end{array}$ \\
\hline
\end{tabular}


ISSN: $2594-4827$

\begin{tabular}{|l|l|l|}
\hline & $\begin{array}{l}\text { quanto do aluno, depende da parte do aluno } \\
\text { também. }\end{array}$ \\
\hline
\end{tabular}

Fonte: Autores.

Percebemos que, ao formularem metáforas sobre o Pronatec, os docentes também estão se referindo ao seu próprio trabalho. No contexto da TRS, as metáforas podem atuar na construção do modelo figurativo da representação (MOSCOVICI, 1976/2012), oferecendo pistas para os processos de ancoragem e de objetivação. Mazzotti (1995) acredita na produção do conhecimento através da metaforização, por isso indica as metáforas nas investigações sobre representações sociais e ressalta a importância da linguagem como agenciadora do processo de representação e transmissão de significados:

Por que metáfora? Porque qualquer processo é invisível, não se apresenta imediatamente para nós, é abstrato, resulta de uma inferência a partir de uma comparação com algo que supomos ser mais visível. (MAZZOTTI, 2008)

Os processos de objetivação e de ancoragem se relacionam. E a objetivação, particularmente, está no modelo figurativo, um esquema de organização do pensamento. $\mathrm{O}$ modelo, posteriormente chamado também de núcleo figurativo, proposto por Moscovici (2012, p. 114), “é não só uma maneira de classificar as informações, mas o resultado da coordenação que caracteriza cada termo da representação”. De acordo com o autor,

ao penetrar no meio social como expressão do "real", o modelo figurativo se torna então "natural", utilizado como se fosse copiado diretamente dessa realidade. A conjunção de dois movimentos, o da generalização coletiva de uso e o da expressão imediata dos fenômenos concretos, permite à representação tornar-se um aparato cognitivo estável e orientar as percepções ou as opiniões sobre o comportamento ou as relações interindividuais (MOSCOVICI, 2012, p. 115).

No conjunto do material, ao se referirem ao trabalho que exercem no Pronatec, a metáfora "sair da caixinha", também acompanhada por outra metáfora, "ter jogo de cintura", apareceu nos discursos com o sentido de ser usada como uma estratégia para conseguir formar pessoas. Isto significa encontrar os meios de fazer com que os professores possam promover um avanço, uma diferença no modo de pensar e agir, para atingir algum crescimento e amadurecimento nos alunos, repensando as suas aulas e o próprio curso técnico. Portanto, "ter jogo de cintura" torna-se essencial para seguir e garantir algum desenvolvimento nos alunos, "fazer o broto da planta crescer". 
ISSN: $2594-4827$

Com base nas falas citadas e com fundamentação na TRS, foi possível propor o seguinte modelo figurativo das representações sociais de docentes sobre seu trabalho no Pronatec (Figura 1).

Figura 1: Modelo figurativo das representações sociais dos docentes sobre seu trabalho no Pronatec - uma hipótese interpretativa.

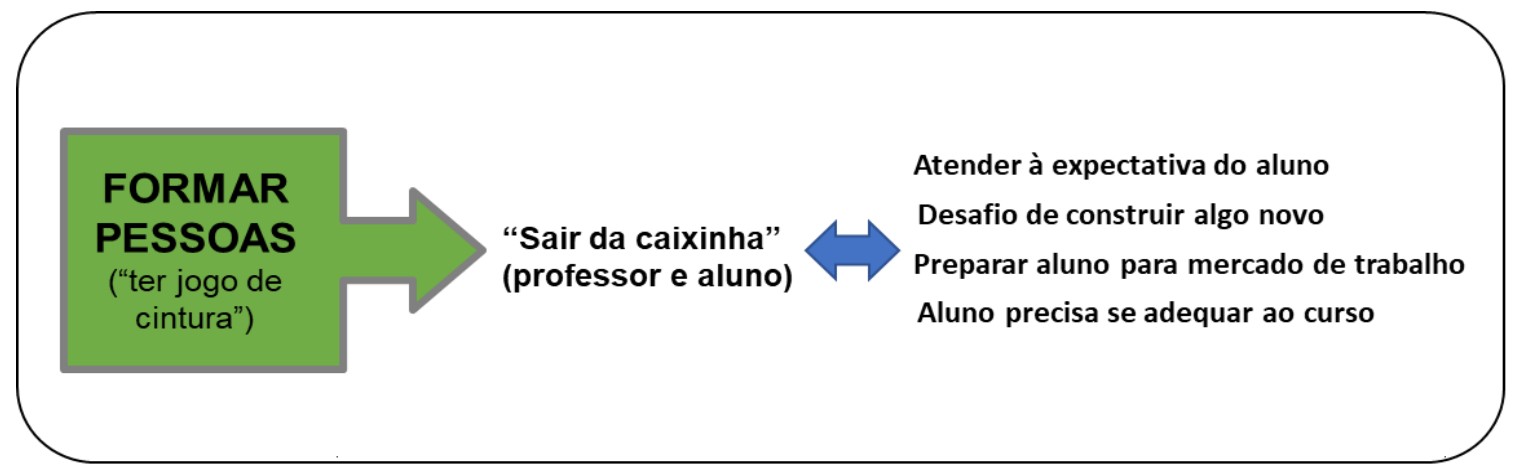

Fonte: autores.

A metáfora BROTO/PLANTA, subjacente ao modelo figurativo, se sustenta na possibilidade de crescimento, de expansão, de construção de algo que precisa de um tempo para se concretizar, para ficar forte, enraizado, dando frutos, distribuindo sementes, ampliando o horizonte. Porém, esse broto plantado apresenta muitas fragilidades, ainda não está seguro o suficiente para se dizer que se adaptou ao solo e enraizou. Há riscos de não vingar, não conseguir crescer e dar frutos. Outro significado dado por uma das entrevistadas é de que o plantio foi feito, mas ninguém sabe identificar qual é a semente, de que fruto ou espécie, portanto não se sabe se o que vai crescer é o esperado, se é interessante e se corresponde às expectativas dos que plantaram.

A expressão "sair da caixinha" surge como uma ousadia, uma tentativa, uma mudança de roteiro, uma abertura para o novo, um olhar otimista, mas realista da situação. Em seu conjunto, os docentes reconhecem que precisam criar novos mecanismos de aprendizagem, tentando compreender essa demanda, ampliando a sua percepção de ensino e de aprendizagem, convidando o outro a construir um novo caminho. São aspectos inerentes a uma planta em crescimento.

Retomando Moscovici (2012), a objetivação é a construção formal de um conhecimento, já a ancoragem é a inserção desse conhecimento em um repertório de crenças já constituído socialmente. Nesse estudo podemos dizer, como hipótese interpretativa, que a objetivação da representação social do grupo de docentes sobre o trabalho que realizavam no 
ISSN: 2594-4827

Pronatec é "sair da caixinha", sustentado pela metáfora de uma "planta em crescimento". Como indícios de ancoragem, podemos supor a precariedade de recursos em sala de aula desses cursos técnicos profissionalizantes, as fragilidades dos alunos advindas da Educação Básica, e a preparação de professores para promoverem o desenvolvimento dos alunos, o que prejudica "a planta em crescimento". A dificuldade para "dar frutos" pode também estar associada à descontuinidade de políticas de EPT.

\section{CONSIDERAÇÕES FINAIS}

Em entrevistas com os docentes desta pesquisa, constatamos que quase todos percebem a EPT como uma grande oportunidade de inserção no mercado de trabalho e de desenvolvimento social do indivíduo, como estratégia para acelerar a busca de uma profissão e assim promover o crescimento econômico do país, ou como primeira etapa na formação profissional do indivíduo. Entretanto, todos também comentaram sobre a "decepção" em encontrar, nas turmas do Pronatec com Ensino Médio concluído, alunos com lacunas básicas de aprendizagem, que não conseguem fazer uma soma ou que não conseguem expressar verbalmente o que pensam, sentem ou necessitam, muitos analfabetos funcionais.

O universo de significados que envolve dificuldade de professores e alunos quando se deparam com a realidade das políticas públicas educacionais e precisam se posicionar sobre os contextos inerentes ao ensino e aprendizagem, mostra a relevância de estudos de representações sociais para a melhor compreensão dos processos psicossociais dos sujeitos envolvidos.

Buscar a representação social de docentes sobre o seu trabalho na EPT pode assim contribuir para o campo educacional. Na medida em que as representações sociais revelam uma visão funcional do mundo, construída por determinado grupo, as pesquisas que se voltam para a educação, baseadas nesse referencial teórico-metodológico, buscam a compreensão dos significados que os sujeitos dão a diversos objetos.

A pesquisa retratou que o grupo de alunos não correspondia às expectativas do próprio Programa, dos docentes e tampouco do mercado de trabalho. Vários professores administraram suas aulas com o intuito de oferecer um ensino de qualidade e de nível acadêmico semelhante ao de um início de uma graduação, o que possivelmente assustou 
alunos, que não se sentiram capazes de acompanhar as aulas e acabaram desistindo do estudo, conforme relatos de alguns.

Houve um encontro de intenções, mas um desencontro de resultados: docentes com desejo de formar pessoas, promover o crescimento social, mas com dificuldades de encontrar um caminho que pudesse fazer sentido para os dois lados no processo de aprendizagem. A diversidade de perfis e a defasagem de aprendizado dos alunos fizeram com que os docentes tivessem que ter "jogo de cintura" para despertar seu interesse. Não podiam perder esses indivíduos que procuravam se qualificar, não podiam desperdiçar a chance de assegurar a eles alguma transformação. O broto da planta precisaria crescer. Para isso eles precisavam "sair da caixinha" para "formar pessoas", "ter jogo de cintura" para "atender à expectativa do aluno", "se desafiar para construir algo novo", para "lidar com a diversidade de alunos", "prepará-los para o mercado de trabalho". Mas também esperavam que o aluno "saísse da caixinha e se adequasse ao curso", tentando driblar as suas limitações.

Dois fatores parecem nortear a reflexão que os dados da pesquisa nos alertaram: a formação insuficiente dos alunos do Ensino Médio para dar continuidade ao Ensino Profissional e Tecnológico e a inadequação da prática docente com a demanda que chega desse Ensino Médio insuficiente, ou seja, não há condições de se garantir a aprendizagem nesses cursos com a qualidade de ensino oferecida pela maioria das escolas públicas.

Destacamos que o público jovem que realizou um Ensino Médio que poderia se adequar a esses cursos, não tem interesse em fazê-los, preferem a graduação e/ou sentem-se pressionados socialmente a fazê-la. Em contrapartida, o público carente de oportunidades, que está distante da graduação, que não teve a oportunidade de realizar um Ensino Médio de qualidade, que mal consegue se expressar, que não tem familiaridade com o saber, com o estudo, continua sem espaço.

Nesse contexto, o Pronatec apresentava propostas ideológicas e contraditórias: considerava a realidade brasileira e a necessidade de milhões de jovens brasileiros em se profissionalizarem, mas deu pouca atenção ao fato que a formação adequada para esses jovens implica uma formação ampla que deveria ser iniciada na Educação Infantil e continuada ao longo dos anos até o Ensino Médio. Formação esta que propiciasse conhecimentos científicos, tecnológicos e culturais para a realização de uma leitura crítica do mundo, integrada a uma formação profissional que lhes permitisse garantir o seu crescimento pessoal e profissional. A 
ISSN: 2594-4827

realidade dura encontrada pelos docentes desta pesquisa gerou uma frustração coletiva, fez murchar a crença em uma sociedade menos desigual.

O Pronatec encontrava-se agonizando e, mais uma vez, o dinheiro público foi em vão, diante da grande evasão de alunos e da redução de novas turmas. Por que será que esbarramos nos mesmos problemas e limitações? Será que realmente há desejo político e até que ponto esse desejo está de mãos dadas com o desejo pedagógico? Qual é o papel do docente nessa descontinuidade da política educacional?

A pesquisa retratou que, inicialmente, os professores estavam interessados e envolvidos com a proposta do Programa, mas ao entrarem em contato com as dificuldades dos alunos e a incerteza quanto à continuidade do projeto, o desânimo deu voz a uma avaliação crítica da experiência docente. Esses resultados reforçam a descontinuidade que ocorre no Brasil em relação a políticas educacionais e as dificuldades dos docentes e dos alunos em se adaptarem à instabilidade dessa situação. A metáfora "broto/planta" condensou esse significado de fragilidade, sustentado na possibilidade de crescimento, de expansão, de construção de algo que ainda precisaria de tempo para dar frutos.

A perspectiva psicossocial, associando a TRS e as narrativas de vida, com seu caráter dinâmico, possibilitou, através da comunicação, compreender processos cognitivos e sociais elaborados nas interações, nas experiências de vida, de docência. A pesquisa evidenciou o movimento do sujeito em atribuir sentido à sua prática e entender as suas percepções e expectativas. Ao escutar os docentes, com fragmentos de vida orientados em função do objeto de estudo e dos movimentos de memória, foi possível perceber os bastidores que envolvem os sujeitos no processo ensino aprendizagem desses cursos. Seus relatos revelaram as características desses indivíduos e do grupo ao qual pertencem. Estudos que associem a TRS com a abordagem (auto)biográfica, particularmente a opção por narrativas de vida, podem indicar pistas que aprofundem essas reflexões e apontem caminhos teóricos e práticos no campo da EPT.

\section{REFERÊNCIAS}

ALVES-MAZZOTTI, Alda Judith. Representações sociais: aspectos teóricos e aplicações à educação. Revista Múltiplas Leituras, v.1, n. 1, p. 18-43, 2008.

ALVES-MAZZOTTI, Alda Judith. Histórias de vida de professores, formação e 
ISSN: 2594-4827

representações sociais: uma proposta de articulação. Revista Educação Pública, v 24, n. 55, p. 81-101, 2015.

ALVES-MAZZOTTI, Alda-Judith; GEWANDSZNAJDER, Fernando. O método nas ciências naturais e sociais: pesquisa quantitativa e qualitativa. São Paulo: Pioneira, 1999.

ANDRADE, Daniela B. da S. F. (2006). O lugar feminino na escola: um estudo em representações sociais. Tese de doutorado, Pontifícia Universidade Católica de São Paulo, São Paulo, Brasil.

BARDIN, Laurence. Análise de conteúdo. Lisboa: Edições Setenta, 1994.

BOURDIEU, Pierre. A miséria do mundo. Tradução de Mateus S. Soares. 3a edição. Petrópolis: Vozes, 1999.

BRAGANÇA, Inês F. S. Histórias de vida e formação de professores: diálogos entre Brasil e Portugal. Rio de Janeiro: EDUERJ, 2012.

BRASIL. Lei n. 1.826 - Diretrizes e Bases da Educação Nacional. Promulgada em 1953.

BRASIL. Lei n. 4.024 - Diretrizes e Bases da Educação Nacional. Promulgada em 20.12.1961.

BRASIL. Lei n. 5.692 - Diretrizes e Bases de Primeiro e Segundo graus de Ensino. Promulgada em 11.08.1971.

BRASIL. Lei n. 9.394 - Diretrizes e Bases da Educação Nacional. Promulgada em 20.12.1996.

BRASIL. Decreto Federal n. 2208, Brasília, 17 de abril de 1997.

BRASIL. Decreto Federal n. 5154, Brasília, 23 de julho de 2004.

BRASIL. MEC. PRONATEC. Programa Nacional de Acesso ao Ensino Técnico e Emprego. 2012. Disponível em: <http://pronatecportal.mec.gov.br/index.html>. Acesso em: 01 out. 2015 .

BRASIL. MEC. PRONATEC. Programa Nacional de Acesso ao Ensino Técnico e Emprego. 2016. Disponível em: <http://pronatecportal.mec.gov.br/objetivos. html>. Acesso em: 13 mai. 2016.

BRASIL. Ministério da Educação. Conselho Nacional de Educação. Educação Profissional: Legislação Básica. Disponível em: http://portal.mec.gov.br/cne/arquivos/pdf/009.pdf> Acesso em: 17 abr. 2016.

CIAVATTA, Maria; RAMOS, Marise. Ensino Médio e Educação Profissional no Brasil: Dualidade e Fragmentação. Revista Retratos da Escola, Brasília, v. 5, n. 8, jan./jun., 2011. p. 36. 
ISSN: 2594-4827

FRIGOTTO, Gaudêncio; CIAVATTA, Maria. Ensino Médio Integrado: Concepções e contradições. São Paulo: Cortez, 2005.

JODELET, Denise. Representações sociais: um domínio em expansão. In: JODELET, D. (org.). As Representações sociais. Rio de Janeiro: Eduerj, 2001. p. 22 - 36.

JOSSO, Marie-Christine. As narrações centradas sobre a formação durante a vida como desvelamento das formas e sentidos múltiplos de uma existencialidade singular-plural. Educação e Contemporaneidade, Salvador, v. 17, n.29, 2008.

JOSSO, Marie-Christine. Experiências de vida e formação. Natal: EDUFRN; São Paulo: Paulus, 2010. p. 175 - 183.

LAKOFF, George; JOHNSON, Mark. Metáforas da vida cotidiana. Campinas: Mercado das Letras, 2002.

LIMA, Marcelo. A Educação Profissional no governo Dilma: Pronatec, PNE e DCNEMs. Trabalho e Educação, Belo Horizonte, v.21, n.2, 2012.

MAZZOTTI, Tarso. Núcleo figurativo: themata ou metáfora? Psicologia da Educação. São Paulo, 14/15, $1^{\circ}$ e $2^{\circ}$ sem., 2002.

MAZZOTTI, Tarso. Doutrinas Pedagógicas: máquinas produtoras de litígios. Marília - SP: Poïesis, 2008.

MOSCOVICI, Serge. La psychanalyse, son image, son public. Paris : PUF, 1961.

MOSCOVICI, Serge. La psychanalyse, son image, son public. $2^{\mathrm{e}}$. édition entièrement refondue. Paris : PUF, 1976.

MOSCOVICI, Serge. Notes towards a description of social representations. European Journal of Social Psychology, v. 18, p. 248, 1988. Tradução Gláucia Alves Vieira.

MOSCOVICI, Serge. Representações sociais: investigações em psicologia social. Editado por Gerard Duveen e Tradução de Pedrinho Guareschi. - 5ª ed. Petrópolis, RJ: Vozes, 2007.

MOSCOVICI, Serge. A psicanálise, sua imagem, seu público. Rio de Janeiro: Petrópolis: Vozes, 2012.

NEVES, Lucia. M. W.; PRONKO, Marcela. A. O mercado do conhecimento e o conhecimento para o mercado: da formação para o trabalho complexo no Brasil contemporâneo. Rio de Janeiro: Escola Politécnica de Saúde Joaquim Venâncio, 2008. p. 24.

SÁ, Celso. P. de. A construção do objeto de pesquisa em representações sociais. Rio de Janeiro: EDUERJ, 1998. p. 19.

SAVIANI, Demerval. História das ideias pedagógicas no Brasil. Campinas, São Paulo: Autores Associados, 2007. 